\title{
SAPOGENINS OF Eryngium octophyllum
}

\section{T. Ikramov, R. L. Khazanovich,}

UDC $547.597+547.918$

and Kh. Kh. Khalmatov

We have previously reported the isolation from the roots of Eryngium octophyllum Eug. Kor. of combined saponins the acid hydrolysis of which gave the combined sapogenins [1], consisting of four substances with $\mathrm{R}_{f} 0.06,0.21,0.38$, and 0.58 , respectively [chloroform-ethyl acetate $(2: 1)$ system].

The sapogenins were separated on a column of silica gel and were eluted from it chloroform-ethyl acetate and then with the same mixture with the addition of increasing amounts of ethanol. All the genins were obtained in the individual state.

A substance with $\mathrm{R}_{f} 0.58$ had $\mathrm{mp} 220-223^{\circ} \mathrm{C}$ and gave an acetate with $\mathrm{mp} 113-116^{\circ} \mathrm{C}$, mol. wt. 572 (mass spectroscopy), which corresponds to the properties of eryngium genin A [2]. The IR spectrum of the substance coincided completely with that of eryngium genin A. According to the literature, eryngium genin $A$ is an ester consisting of $A_{1}$-barrigenol and organic acids [2]. When the substance was saponified with ethanolic alkali, we obtained similar results: $A_{1}$-barrigenol, identified by its $R_{f}$ values, melting point, and IR spectrum [1], and organic acids.

The substance with $\mathrm{R}_{f} 0.21$ had $\mathrm{mp} 304-306^{\circ} \mathrm{C}$ and gave an acetate with $\mathrm{mp} 256-259^{\circ} \mathrm{C}$, mol. wt. 456 (mass spectroscopy). This compound was characterized as oleanolic acid also through its IR spectrum which, on superposition, coincided with the IR spectrum of an authentic sample of oleanolic acid.

The substance with $\mathrm{R}_{f} 0.06, \mathrm{mp} 262-264^{\circ} \mathrm{C}$, mol. wt. 588 (mass spectroscopy) was identified as eryngium genin $C$. This, like eryngium genin $A$, is an ester and is composed of $R_{1}$-barrigenol and organic acids [2]. Saponification with ethanolic alkali gave $R_{1}$-barrigenol and organic acids. The $R_{1}$-barrigenol was identified from its $\mathbf{R}_{f}$, melting point, the preparation of an acetyl derivative, the molecular weight, and the IR spectrum [1].

The substance with $\mathrm{R}_{f} 0.38$ was identified as eryngium genin $\mathrm{D}$ only on the basis of chromatography from its $\mathrm{R}_{f}$ values in a number of solvent systems $\left[\mathrm{R}_{f} 0.48\right.$ in benzene-chloroform-methanol $(3: 3: 0.5)$, and 0.67 in chloroform-methanol $(11: 1)]$ because of the very small amount available.

Thus, the saponins from the roots of Eryngium octophyllum are triterpenes; three of the sapogenins are esters consisting of the alcohols $A_{1}$-barrigenol and $R_{1}$-barrigenol with organic acids and the fourth is olẹanolic acid.

\section{LIT ERATURE C IT ED}

1. M. T. Ikramov, R. L. Khazanovich, and Kh. Kh. Khalmatov, Khim. Prirodn. Soedin., 843 (1971).

2. K. Hiller, M. Keipert, S. Pfeifer, L. Tökes, and M. L. Maddox, Pharmazie, 25, 769 (1970).

Tashkent Pharmaceutical Institute. Translated from Khimiya Prirodnykh Soedinenii, No. 5, pp. 678679, September-October, 1973. Original article submitted March 16, 1973. 